\title{
O PONTO DE VISTA ENUNCIATIVO SOBRE A LINGUAGEM: a modalização no discurso da Igreja Universal do Reino de Deus
}

Jorge Luís Torresan

\author{
Mestre em Lingüística Aplicada \\ pelo Programa de Estudos Pós- \\ Graduados em Lingüística \\ Aplicada e Estudos da Linguagem \\ (LAEL) - PUC-SP; \\ Professor de Leitura e Produção \\ Textual - Uninove.
}

\begin{abstract}
Resumo
No universo dos estudos da Lingüística, encontramos uma série de possibilidades de ordem teórico-metodológica para analisar os discursos que nos envolvem e nos quais nos envolvemos. Por meio da Análise de Discurso, este artigo traz uma reflexão sobre o discurso que uma das igrejas do movimento evangélico brasileiro propõe para os seus fiéis à luz dos aspectos da modalização, mostrando como uma determinada instituição religiosa, por meio de um processo de manipulação da linguagem, consegue aprisionar as atenções de um grande número de pessoas.
\end{abstract}

\section{Palavras-chave}

Discurso. Enunciação. Modalização. Subversão.

\section{THE ENUNCIATIVE POINT OF VIEW ABOUT LANGUAgE: The modalization into} the universal church of kingdom of god discourse

\begin{abstract}
Within the universe of Linguistics we find several theoretic-methodological possibilities to analyze the discourses that involve us and which we get involved in. Fundamented on the Discourse Analysis using modalization aspects this article elicits a reflection on the discourse that one evangelical church uses with its followers on the modalization aspects showing as the processes of manipulation happens by means of language, better, how a specific religion institution gets to catch attention of a great number of people.
\end{abstract}

\section{Key words}

Discourse. Enunciation. Modalization. Subversion. 


\section{Introdução}

A ação dos sujeitos na sociedade, desde os atos mais simples até os mais complexos, se faz na e pela linguagem. Esta afirmação privilegia a concepção de linguagem como 'trabalho' e não apenas como ‘suporte do pensamento' que vê, no processo de criação lingüística, um ato exclusivamente individual, sem considerar os elementos contextuais de uma situação social - o lugar de onde se fala, para quem se fala, com que finalidade se fala -, excluindo definitivamente o 'outro' e, assim, acentuando o caráter monológico da linguagem.

Por meio da linguagem, os sujeitos agem num determinado contexto sócio-histórico, transformando continuamente esse contexto numa ação interativa com outros sujeitos. Saber servir-se da linguagem e de seus múltiplos mecanismos de funcionamento como trabalho interativo pode ser uma poderosa ferramenta com a qual os sujeitos garantem espaços no meio em que atuam, permitindo que suas vozes sejam ouvidas, controlando ou até mesmo apagando outras e, dessa forma, instaurando algumas situações, como o controle e/ou o autoritarismo.

O resultado desse processo interativo, desse trabalho com a linguagem é a produção de discursos, cuja finalidade deixa de ser, em muitos casos, a simples comunicação gratuita, agregando a criação de efeitos de sentido, afinal "a linguagem enquanto discurso é interação, é um modo de produção social; ela não é neutra, inocente (na medida em que está engajada numa intencionalidade) e nem natural, por isso o lugar privilegiado da ideologia." (BRANDÃO, 1996, p. 12).

Estudos sobre o discurso têm sido o alvo de várias áreas do conhecimento, cada uma delas com suas preocupações e abordagens específicas, tais como a Psicologia, a Filosofia, a Política, a História, a Lingüística e tantas outras que vêem o discurso como um valioso e fundamental elemento da produção humana.

A Lingüística, ciência que particularmente nos interessa aqui, deu um salto considerável e muito produtivo nos estudos sobre o discurso, principalmente no momento em que rompeu com os limites teóricos necessários, inicialmente estabelecidos por Saussure, que tomou a língua (langue) como único objeto de estudo em oposição à fala (parole), por considerá-la individual e momentânea, subordinada à língua - de caráter coletivo. 
Combinando a inclusão da fala com o rompimento de análises puramente estruturalistas que se restringiam aos limites da frase, a Lingüística amplia seu campo de estudo, possibilitando, assim, a abertura para uma série de disciplinas que abordam a linguagem e sua manifestação em seus vários aspectos, contemplando, além da materialidade lingüística, outros elementos de ordem extralingüística de grande importância, como o social, o contexto dos que interagem, o fator histórico e o sujeito. Cabe ao analista avaliar esse intrincado universo da linguagem e seu funcionamento nas mais diversas esferas e situações sociais, pois

desde o momento em que se passa a tratar a linguagem como um objeto autônomo, aceitando a separação radical feita por Saussure entre a lingüística interna e a externa, entre a ciência da língua e a ciência dos usos da língua, fica-se condenado a buscar o poder das palavras nas palavras, ou seja, a buscá-lo onde ele não se encontra. (BOUDIEU, 1996, p. 85).

Nesse sentido, Fonética/Fonologia e Morfologia e Sintaxe, áreas pioneiras e tradicionais da Lingüística, dão espaço para outras tantas disciplinas como a Semântica, a Sociolingüística, a Psicolingüística, a Análise da Conversação e a Análise do Discurso que, com suas várias linhas teóricas, vê no discurso a união dos aspectos lingüísticos atrelados aos aspectos sociais e históricos, que pode ser entendida como "a tentativa de ruptura de duas barreiras: a que impede a passagem da frase ao discurso e a que separa a língua da fala, ou melhor, dos fatos sócio-históricos que a envolvem." (BARROS, 1988, p. 2).

\section{A modalização: uma eficiente ferramenta de análise}

A definição de linguagem como trabalho revela um posicionamento pragmático, pois estamos considerando a linguagem como uma atividade ou uma forma de ação que coloca em cena o agente dessa ação e que, por sua vez, põe a língua em funcionamento, uma 
vez que "todo discurso é um ato: ao produzi-lo, o locutor cria para o destinatário determinadas obrigações, definindo o quadro dentro do qual o discurso deverá se desenvolver.”' (KOCH, 1981, p. 05).

Quando a Lingüística reconheceu e assumiu o fato de que ao sujeito cabe o papel de agente de ações por meio do discurso, estabelecendo as relações entre destinador e destinatário, ou, se preferirmos, locutor e interlocutor, ela definitivamente impôs uma fronteira entre duas formas de fazer um estudo lingüístico que podem ser indicadas pelas rubricas: lingüísticas não enunciativas e lingüísticas enunciativas.

Os mais significativos porta-vozes das lingüísticas não enunciativas são os representantes do movimento estruturalista. Para Cervoni (1989, p. 9-10), por exemplo,

a lingüística devia limitar-se ao estudo da língua em si mesma e por si mesma, uma vez que a língua devia ser definida como um sistema de signos e de regras, tesouro coletivo depositado em cada cérebro, conjunto de convenções próprias de todos os locutores de um mesmo idioma, código único e homogêneo que lhes permite comunicarem-se.

Mikhail Bakhtin (1999, p. 109) é, sem dúvida, um importante nome a ser citado quando o assunto é o posicionamento enunciativo sobre a linguagem, pois, para esse pensador russo, "na realidade, o ato de fala, ou, mais exatamente, seu produto, a enunciação, não pode de forma alguma ser considerado como individual no sentido estrito do termo; não pode ser explicado a partir das condições psicofisiológicas do sujeito falante. A enunciação é de natureza social." Ao conceber a enunciação como uma questão de natureza social, Bakhtin (op. cit., p. 113) propõe a descentralização de um sujeito tido como senhor e centro absoluto de seu discurso, passando a considerar o 'Eu' imerso num processo de interação verbal, no qual o 'Outro' possui papel ativo na constituição do sentido discursivo, já que

toda a palavra comporta duas faces. Ela é determinada tanto pelo fato de que procede de alguém, como pelo fato de que se dirige para alguém. Ela constitui justamente o produto da interação do locutor e do ouvinte. Através da palavra, defino-me 
em relação ao outro, isto é, em última análise, em relação à coletividade. A palavra é uma espécie de ponte lançada entre mim e os outros [...] A palavra é o território comum do locutor e do interlocutor.

Nesse sentido, vemos que a Lingüística, preocupada com o aspecto enunciativo da linguagem, por meio de orientação pragmática, privilegia os aspectos antes relegados, como o locutor, a relação que este estabelece com o seu interlocutor, a atitude desse locutor diante de seu enunciado (Косн, 1981). Vários são os mecanismos lingüísticos dos quais o sujeito se serve para marcar sua presença no discurso e, conseqüentemente, várias são as possibilidades e os mecanismos por meio dos quais o analista de discurso pode apreender esse sujeito, suas formas de manifestação e de construção do discurso e, principalmente, os efeitos de sentido que ele pretende causar em seu interlocutor. Entre essas várias formas, Koch (op. cit., p. 6) destaca a

modalização que define as marcas que o locutor imprime ao enunciado, por intermédio de recursos lingüísticos capazes de traduzir o processo de enunciação, indicando o grau de adesão que presta ao seu discurso. O maior ou menor grau de adesão é manifestado através dos modalizadores.

O sujeito de um discurso, dependendo de suas necessidades comunicativas, para desenvolver seu trabalho com a linguagem numa relação interativa com outros sujeitos, põe em ação um verdadeiro arsenal de mecanismos da linguagem; ao empregá-los, deixa, em maior ou menor grau, vestígios de sua presença e, de alguma forma, de seu projeto de fala (suas intenções) que pode ser detectado por meio das marcas lingüísticas apostas no seu discurso, ou seja, o sujeito sempre deixa vestígios da forma como modaliza seu discurso para suprir suas necessidades comunicativas.

Tendo em vista sua importância e pertinência, a modalização constituiu fonte de interesse para três áreas do conhecimento: a Lógica, a Linguiística e a Semiótica. A Lógica, que pode ser representada por Aristóteles, foi a primeira a refletir sobre a modalização com objetivos centrados na tentativa de evitar os ‘acidentes' da linguagem, enquanto à Lingüística coube a tarefa de levar em conta os signos empregados 
para exprimir as várias modalidades numa língua natural e analisar suas possibilidades de utilização do léxico, tendo que enfrentar questões de ambigüidade ou de polissemia (KOCH, 1981).

Cervoni (1989) aponta os motivos que levaram a Lingüística contemporânea a revisitar as modalidades depois de seu eclipse oriundo do período próspero do estruturalismo. As modalidades ressurgiram graças: 1) ao desenvolvimento das pesquisas sobre lógica da linguagem, destacando-se os trabalhos da semântica gerativa; 2) ao interesse dos lingüistas pela análise do que se faz ao falar, destacando-se, nesse contexto, os trabalhos do filósofo inglês John Austin $(1971,1979,1990)$ sobre a performatividade; 3$)$ ao desenvolvimento da Semiótica preocupada com a narratividade do discurso, sendo de grande importância as noções expressas pelos verbos 'querer', 'dever', 'poder', 'saber' na descrição dos tipos de atitudes para explicar o funcionamento da narrativa.

Se por um lado as modalidades podem seduzir o analista de discurso, devido à sua pertinência para a análise, por se tratar de uma forma de flagrar as concepções da Teoria da Enunciação, revelando-nos, por meio de marcas lingüísticas, o grau de adesão do locutor ante o seu discurso, a abordagem das modalidades tem também demonstrado ser um campo meio movediço, pois ao longo da evolução da Lingüística houve uma mudança considerável na descrição das operações utilizadas, responsáveis pela modalização dos enunciados, dificultando, assim, a elaboração de uma teoria unificada sobre a questão. Um questionamento já é suficiente para demonstrarmos essa dificuldade no trato com as modalidades: Onde incluí-la? Na sintaxe? Na semântica? Na pragmática?

Não temos aqui a pretensão de discorrer exaustivamente a fim de propor uma resposta a essa questão. O que fazemos é concordar com o posicionamento de Darrault (apud KOCH, 1981, p. 96-97) que afirma:

se essa trilogia de disciplinas se impõe de início como a tipologia mais cômoda para distinguir os diferentes tratamentos da modalidade, na prática, ela se revela pouco satisfatória na medida em que um número cada vez maior de trabalhos aparecem como dificilmente classificáveis. Prova, sem dúvida, de que as barreiras estão em vias de cair, de que se 
impõe cada vez mais a idéia de que, no domínio das modalidades, não é mais possível imaginar soluções estritamente monodisciplinares.

Atribuímos às modalidades, concordando com as discussões de Guimarães (1979), o caráter de estratégias argumentativas. E se pensarmos no discurso da Igreja Universal do Reino de Deus, ${ }^{1}$ veremos que o pastor modaliza todo o discurso com a finalidade de conquistar a atenção de seu fiel. Estamos interessados em observar justamente como essa modalização é feita.

Quando falamos em modalização, é muito comum lembrarmos imediatamente das clássicas designações propostas pela Lógica que é também levada em conta pela Lingüística, ou seja: 1) aléticas - aquelas que se referem à verdade do conteúdo das proposições; 2) epistêmicas - que operam com os valores da crença, da certeza, daí os verbos 'crer' e 'saber' como os melhores para exprimir essa forma da modalidade; 3) deônticas - que operam com os valores que dizem respeito à conduta, às normas, às proibições, nas quais os principais verbos empregados são poder e dever.

Entretanto, não desconsiderando esse tratamento usual das modalidades, ou seja, perseguir um discurso procurando determinar apenas se o que predomina é a modalização alética, epistêmica ou deôntica, acreditamos que seja muito mais produtivo, para a análise aqui proposta, buscar outras marcas lingüísticas deixadas pelo pastor em seu discurso que nos permitam entender seu projeto de fala (intenções) dirigido ao fiel.

\section{As citações bíblicas no discurso da Igreja Universal do Reino de Deus: uma estratégia modalizadora do discurso}

Nos limites deste trabalho, abordaremos a modalização no discurso da Igreja Universal do Reino de Deus, perseguindo as citações bíblicas utilizadas pelo pastor. ${ }^{2}$

\footnotetext{
2 Este artigo é apenas um recorte da análise feita do discurso da Igreja Universal do Reino de Deus extraído da Dissertação de MestradoapresentadaaoPrograma de Estudos Pós-Graduados em Lingüística Aplicada e Estudos da Linguagem (LAEL), da Pontifícia Universidade Católica de São Paulo (PUC-SP), no final de 2001. Os recortes dos discursos dos pastores fazem parte de uma produção dessa Igreja publicada no jornal Folha Universal - um jornal a serviço de Deus, de propriedade da referida Igreja.
} 
Observando a estrutura composicional do discurso da Igreja Universal transmitido pela voz de seus pastores, veiculado no jornal Folha universal - um jornal a serviço de Deus, nota-se o uso freqüente de citações extraídas da Bíblia. Trata-se de um discurso que, a todo momento, recupera a voz de Deus ou de alguns personagens bíblicos que se destacaram pela demonstração de fé e coragem na grande narrativa divina. Uma possível justificativa para o uso excessivo dessas citações pode vir da própria história dos evangélicos, cujo berço é a Reforma Protestante. O afastamento da Igreja Católica dos preceitos bíblicos que se traduziram, segundo os reformadores, na criação de dogmas que desvirtuaram os reais preceitos cristãos, foi um dos principais motivos que conduziram alguns grupos do próprio Catolicismo para o protesto das ações da Igreja, culminando na Reforma Protestante (ou Protestantismo), em 1517. A principal reivindicação dos reformadores (ou dos protestantes) era o retorno ao seguimento irrestrito dos preceitos da Bíblia. Dessa forma, o uso constante de passagens bíblicas reflete a tentativa de provar, a todo instante, o resgate e o seguimento da verdadeira palavra de Deus. Contudo, como veremos mais adiante, a julgar pela forma como a Igreja Universal constrói seu discurso, ou seja, por meio de uma interpretação desvirtuosa da Bíblia, ela acaba por infringir uma das principais normas de seus antecessores evangélicos que é justamente pregar a palavra de Deus ipsis litteris ou, pelo menos, não dar tantas asas à imaginação na interpretação das muitas metáforas nela encontradas.

Por ser um texto predominantemente metafórico, fica muito difícil e complicado propor uma interpretação que traduza a real intenção daqueles que redigiram o texto bíblico, pois poderíamos ser interrogados sobre o desvio da interpretação proposta pela Igreja Universal a que nos referimos. Dessa possível contra-argumentação nos defenderíamos apontando para a inegável influência dos preceitos da Teologia da Prosperidade 3 no discurso dos pastores, haja vista a presença freqüente, no discurso da Igreja Universal, do apelo ao campo financeiro - afinal, como justificar o rápido e notório crescimento financeiro da Igreja Universal que, como quase toda instituição religiosa, vive principalmente da arrecadação do dízimo de seus fiéis seguidores? Se a interpretação das metáforas bíblicas

3 O Evangelho da Prosperidade,
também chamado por outros
teóricos de Teologia da
Prosperidade, Ensino de Fé,
Palavra de Fé, Confissão Positiva,
trata-se de um movimento
que "surge para oferecer
uma compreensão distinta do
evangelho de Cristo como um
todo. À semelhança do conhecido
evangelho, ela proclama boas
novas. Mas as novas não são de
que temos o perdão dos pecados e
paz com Deus por meio de Cristo.
São de que podemos ter a solução
de nossos problemas e viver com
saúde e prosperidade" (PIERATT,
1999, p. 13). O problema dessa
teologia é que os estudos teológicos
a apontam como má e distorcida
interpretação dos preceitos bíblicos
a favor da criação de uma doutrina
que ensina a seus seguidores que o
homem foi colocado na Terra para
viver em abundância, com fartura
e prosperidade.

3 O Evangelho da Prosperidade, também chamado por outros teóricos de Teologia da Prosperidade, Ensino de Fé, Palavra de Fé, Confissão Positiva, trata-se de um movimento que "surge para oferecer uma compreensão distinta do evangelho de Cristo como um todo. À semelhança do conhecido evangelho, ela proclama boas novas. Mas as novas não são de que temos o perdão dos pecados e paz com Deus por meio de Cristo. São de que podemos ter a solução de nossos problemas e viver com saúde e prosperidade" (Pieratt, 1999, p. 13). O problema dessa teologia é que os estudos teológicos a apontam como má e distorcida interpretação dos preceitos bíblicos a favor da criação de uma doutrina que ensina a seus seguidores que o viver em abundância, com fartura e prosperidade. 
apenas incutisse no fiel a idéia de um cristão simples, de sandálias nos pés, comendo pão e peixe e fazendo caridade sem se preocupar com o aspecto material, é evidente que o resultado desse discurso não faria com que algumas igrejas se tornassem grandes empreendimentos religiosos.

Usar ou não o texto bíblico como fonte e suporte para o discurso das igrejas evangélicas é uma questão de cunho teológico e de livre escolha dessas igrejas. O problema surge justamente quando se opta por esse uso apenas para justificar as origens históricas dessas igrejas, e o trabalho do analista é questionar o objetivo desse discurso que, segundo os pastores, seria para justificar tão-somente as origens históricas dessas religiões, ou seja, deixar sempre latentes os desejos do protestantismo pioneiro, sempre vinculado ao texto bíblico. Resposta um tanto ingênua se pensarmos nas igrejas de hoje, principalmente na Igreja Universal. Observando melhor o discurso de seus pastores, percebe-se que esse uso das citações bíblicas serve muitas vezes para camuflar um objetivo implícito maior que é incutir no fiel a possibilidade de transformação financeira de sua vida, pois o verdadeiro cristão, na concepção da Igreja Universal, não pode aceitar o fato de ser pobre, já que é filho de um pai poderoso - Deus -, portanto um co-herdeiro com Jesus Cristo, ocorrendo, então, uma subversão do texto bíblico (da ideologia cristã) em prol da criação de uma doutrina específica influenciada pelas idéias da Teologia da Prosperidade.

Antes de demonstrarmos como essa subversão é feita, convém salientar que o emprego das citações é, sem dúvida, uma forma de o locutor modalizar seu discurso, pois, a serviço dos seus objetivos, ele seleciona, entre tantas, algumas citações que melhor possam contribuir para a criação do efeito de sentido desejado.

Outro ponto muito importante a ser levantado diz respeito à especificidade do discurso citado. Essa questão foi - e ainda é - fonte de discussões em Lingüística. Muito mais do que simplesmente entendido como um texto em outro texto, numa relação puramente intertextual, o discurso citado deve ser compreendido como "o discurso no discurso, a enunciação na enunciação, mas é, ao mesmo tempo, um discurso sobre o discurso, uma enunciação sobre a enunciação" (BAKHTIN, 1999, p. 144). 
Em Marxismo e filosofia da linguagem, especificamente no capítulo 9, denominado "O discurso de outrem", Bakhtin (op. cit., p. 148) mostra a importância e a relevância que possui a observação do emprego que um locutor faz da palavra do outro, fato esse que nos permite flagrar o dialogismo a que ele se refere, pois, perseguindo o emprego do discurso citado, estaremos perseguindo

a interação dinâmica dessas duas dimensões, o discurso a transmitir e aquele que serve para transmiti-lo, o que reflete a dinâmica da inter-relação social dos indivíduos na comunicação ideológica.

Insistimos novamente no fato de que o discurso da Igreja Universal, empregando os preceitos da Teologia da Prosperidade, subverte o texto bíblico em prol da criação de uma doutrina própria muito sedutora e tentadora para o fiel. Vejamos, então, como a Igreja Universal estabelece o diálogo entre essas duas fortes vozes: a que resgata a ideologia cristã (por meio das citações bíblicas) e a que põe em cena a Teologia da Prosperidade (por meio da seleção lexical feita pelo pastor em suas pregações).

Para fazer com que essa doutrina, que visa à prosperidade do fiel, esteja presente em seu discurso, a Igreja Universal se apóia em citações bíblicas cuidadosamente selecionadas. São trechos da Bíblia que, em geral, possuem alguma palavra ou expressão que permitam ao pastor propor uma interpretação do texto bíblico que resgate, de alguma forma, as concepções da Teologia da Prosperidade. Em outros termos, isso significa dizer que, ao propor um referente que explicitamente parece refletir a doutrina cristã, o pastor, na verdade, utilizando-se dessa malha intertextual, trata implicitamente de um outro referente que é a constante possibilidade de uma transformação (financeira) na vida do fiel. Vejamos como isso acontece, acompanhando como o discurso da Igreja Universal vai definindo conceitos fundamentais como fé, prosperidade, sacrifício, apoiando-se nas citações retiradas da Bíblia.

Para mostrar a forma como o pastor interpreta o texto bíblico, trasncrevemos alguns momentos de alguns dos discursos compostos de uma citação bíblica feita pelo próprio pastor (sem ele mencionar a fonte) e posterior comentário sobre a referida citação. Para melhor visualizar essa interpretação, esses momentos discursivos foram 
segmentados e dispostos em quadros contendo, na primeira coluna, a citação bíblica feita pelo próprio pastor e, na segunda, um trecho do comentário do pastor apoiando-se na citação. ${ }^{4}$

Para sustentar a concepção de fé da Igreja Universal, aquela que deve ser firme, irrestrita e constantemente comprovada pelo fiel, o pastor seleciona a seguinte citação e, em seguida, tece seu comentário em um dos seus discursos:

4 Considerando que o maior interesse neste artigo é evidenciar a forma como o pastor interpreta passagens do texto bíblico de forma muito peculiar, resolveuse não transcrever os discursos usados para a análise na íntegra, e sim apenas alguns trechos mais significativos para esta discussão.

\section{Citação bíblica}

"Assaltaram-me no dia da minha calamidade, mas o Senhor me serviu da amparo. Trouxe-me para um lugar espaçoso; livrou-me, porque ele se agradou de mim." (SALMOS, 18, 18-19).

\section{Trecho dos comentários do pastor}

"Caro leitor, note que o texto fala em um lugar espaçoso.

O que significa isso? Significa que Deus nos conduz a um lugar de fartura, à prosperidade. Aquele que se diz cristão, entretanto, não pode aceitar o fato de ter um Pai rico e levar uma vida miserável. Isso seria ignorância da sua parte."

Com essa citação o pastor faz com que o fiel entenda "assaltaram-me no dia da minha calamidade" como o surgimento de um problema grave na vida da personagem bíblica, porém o Senhor o amparou, conduzindo-o para um "lugar espaçoso" que deve ser entendido pelo fiel como sinônimo de fartura e prosperidade, palavras que imediatamente põem em cena o campo financeiro, a posse material. Há, nesse discurso, uma nítida proposta de mostrar ao fiel que a obtenção de bens materiais é possível. Isso fica muito claro quando, um pouco mais adiante, o próprio pastor diz ainda: "Talvez você esteja muito preocupado em arrumar um emprego enquanto Deus tem planos de lhe dar uma empresa." Novamente, a escolha lexical feita pelo pastor para elucidar a citação bíblica: as palavras emprego e empresa seduzem demais o fiel, levando-o a acreditar que sua pobreza não é fruto de uma política econômica mal resolvida 
pela qual passa o país, e sim do fato de ignorar que ser cristão filho de Deus lhe dá o direito de adquirir tudo aquilo de que precisa para sanar seus problemas materiais.

Num outro discurso, o pastor propõe a seguinte citação sobre a qual tece seu discurso:

\section{Citação bíblica}

"Passando Pedro por toda parte, desceu também aos santos que habitavam em Lida. Encontrou ali certo homem, chamado Enéias, que havia oito anos jazia de cama, pois era paralítico. Disse-lhe Pedro: Enéias, Jesus Cristo te cura! Levanta-te e arruma o teu leito. Ele, imediatamente, se levantou. Viram-no todos os habitantes de Lida, os quais se converteram ao Senhor." (ATOS, 9, 32-35).

\section{Trecho dos comentários do pastor}

"Antes de observarmos essa passagem, convém entender que a palavra 'santo' significa 'separado' para Deus. Quando a pessoa tem um encontro com o Senhor Jesus e se converte, a partir daí passa a ser santo. Assim, o texto mostra que Pedro, ao encontrar-se com Enéias, não orou, apenas ministrou; e, crendo, o paralítico foi curado. Prezado leitor, talvez esse processo não tenha demorado mais do que dois segundos. É por isso que nós, da Igreja Universal, somos decisivos em nossa fé e não aceitamos o fracasso nem a derrota. O Deus que temos apresentado para o povo é infinitamente grande e poderoso. Ele é o Deus do impossível e tem o desejo de fazer por você muito mais do que possa imaginar."

Com a citação extraída do livro dos Atos, o pastor novamente tenta fazer de uma personagem bíblica, agora Enéias - que fora curado de uma doença apenas com a sua demonstração de fé -, o exemplo a ser seguido pelo fiel. Além de encontrarmos um tom que incentiva e desafia o fiel a agir, o discurso do pastor também mostra a ele que o ocorrido com Enéias é totalmente possível aqui no mundo real, utilizando expressões que o fazem entender que a fé pode muito 
mais do que curar uma doença, pois o Deus ao qual o pastor se refere é o Deus do "impossível”, "infinitamente grande” e "poderoso", aquele que tem o desejo de "fazer muito mais" do que o fiel possa imaginar. A cura da doença de Enéias funciona apenas como um exemplo do que é possível conquistar, mas no fundo o que o pastor pretende com a utilização desse fato ocorrido com a personagem da Bíblia é fazer com que o fiel pense que tudo pode ser alcançado, inclusive sem o eventual receio de estar pedindo a Deus mais do que mereça.

Em um outro discurso, encontramos a seguinte citação bíblica servindo de apoio para o discurso do pastor:

\section{Citação bíblica}

“[...] a fé é a certeza de coisas que se esperam, a convicção de fatos que se não vêem.” (HEBREUS, 11, 1).

\section{Trecho dos comentários do pastor}

“Em outras palavras, fé é certeza, é convicção de que Deus irá fazer exatamente aquilo que Ele prometeu! A fé não pode ficar apenas na base da teoria; dizer que se crê em Deus pura e simplesmente não evidencia de fato a fé. Há algo mais que se tem de fazer para essa fé ficar caracterizada, uma vez que a fé sem obras é morta. É exatamente aí que entra o sacrifício: ele identifica a fé de quem o realiza e ninguém é capaz de fazer um sacrifício sem que esteja convicto dos frutos dele. A Bíblia mostra que os heróis da fé fizeram sacrifícios em razão da crença que tinham no coração."

Preocupando-se com a definição de fé, o pastor usa uma citação extraída do livro dos Hebreus que deixa entrever que a fé é convicção. Sobre essa convicção o pastor vai acrescentando pontos fundamentais da ideologia da Igreja Universal que, por sua vez, resgata a da Teologia da Prosperidade, que é a idéia de sacrifício. Subentende-se que, para alcançar o que deseja, o fiel deve não apenas crer, mas também mostrar, na prática, a sua fé. Há um fundo mercenário no discurso do pastor quando afirma que ninguém faz um sacrifício sem que "esteja convicto dos frutos" que possa oferecer. Aqui se reafirma o que a Teologia da Prosperidade propõe, 
ou seja, que o fiel deve exigir de Deus que o retorno de sua fé seja nas mesmas proporções de seu sacrifício: quanto mais o fiel oferecer para a igreja, mais ele poderá receber de Deus.

Mais adiante, no mesmo trecho de discurso apresentado no quadro anterior, o pastor novamente se manifesta em relação ao sacrifício, afirmando que ele "é o preço da conquista, porque no sacrifício há ação da fé. Nenhum trabalhador teria coragem de sacrificar oito horas por dia durante todo o mês sem que estivesse convicto de receber, no fim do mês, o salário referente àquele trabalho." Aqui se repete o cuidado que o pastor tem com a seleção lexical para interpretar a citação bíblica, empregando termos como "trabalhador', "oitos horas por dia", "receber no fim do mês", "salário", muito bem conhecidos da grande maioria da população que sofre com os reveses financeiros de nossa sociedade. Fatalmente, o fiel se identifica com esse perfil criado pelo discurso do pastor, sentindo-se muito atraído pela possibilidade de transformação a que tanto esse discurso sedutor e tentador se refere.

Num outro discurso, após iniciar a sua fala afirmando que "tudo na vida tem o seu preço, ou o seu valor, e ninguém consegue adquirir coisa alguma neste mundo, e nem no vindouro, sem que se pague o seu preço", o pastor cita e, em seguida, comenta:

\section{Citação bíblica}

"O próprio Senhor Jesus disse isso, em outras palavras, quando afirmou: 'E quem não toma a sua cruz e vem após a mim não é digno de mim'.” (MATEUS, 10, 38).

\section{Trecho dos comentários do pastor}

"Tomar a cruz e ir após Ele é nada mais e nada menos que conservar a salvação, pagando o preço da própria renúncia de cada dia; renúncia esta da sua própria carne ou vontade. No que diz respeito a outras bênçãos, quer espirituais como o batismo com o Espírito Santo, quer financeiras como a conquista de muito sucesso, quer físicas como a cura de uma doença, quer sentimentais como um ótimo casamento, somente se consegue através de uma luta árdua e constante daquele que as deseja de todo o coração. Esta luta árdua e constante é o preço 
que cada um tem que pagar para obter bênçãos. Não se pode simplesmente fazer uma oração e ficar esperando que as coisas aconteçam."

Notemos que, na abertura do discurso do pastor, há o uso de expressões muito sugestivas para a criação de uma interpretação do que seja o sacrifício na vida do fiel, aproximando-a do campo financeiro: "tudo na vida tem o seu "preço"”, “[...] sem que se 'pague' o seu 'preço'”; é como se o sacrifício, na Igreja Universal, significasse exatamente contribuir financeiramente, e não apenas fazer uma oração, passar por um período de abstinência e ficar esperando que as coisas aconteçam.

Podemos, então, concluir que, de acordo com a ideologia da Teologia da Prosperidade, para que o fiel possa conquistar a transformação em qualquer área de sua vida - sentimental, física, financeira etc. - , ele precisa ter fé; entretanto, trata-se de uma fé que deve ser comprovada por meio de sacrifícios que, por sua vez, têm de ser nas mesmas proporções do valor e do tamanho daquilo que é desejado pelo fiel, sem a imposição de condições - tem que ser o 'tudo' do fiel, entendido como doação material. Sabemos que a interação Homem x Deus não é possível em termos reais, ou seja, os homens enquanto ocupantes de um plano material (terreno) não têm acesso direto a Deus, ocupante do plano espiritual; por isso, os homens necessitam de alguém ou de algo que lhes sirva de procurador junto a Deus. As religiões com suas igrejas acabam realizando esse papel e é justamente para elas que o 'sacrifício' é dado ou ofertado. Quanto maior o desejo de transformação, maior terá de ser a fé e o sacrifício do fiel, ou seja, maior terá de ser a contribuição à igreja que se compromete a fazer o papel de concretizadora dessa 'relação comercial' entre homens e Deus.

\section{Conclusão}

Antes de encerrar os comentários sobre a forma como a Igreja Universal modaliza o seu discurso empregando as citações bíblicas, é importante que ressaltemos algumas questões a respeito do emprego da citação. Bakhtin (1999), ao tratar da dinâmica da 
inter-relação do discurso a transmitir com aquele que serve para transmiti-lo, fala de duas orientações estilísticas presentes nas narrativas: a linear e a pictória. Na primeira, o grau de autoritarismo e dogmatismo percebido nos discursos é muito maior do que na segunda, isso porque

a tendência fundamental da reação ativa ao discurso de outrem pode visar à conservação da sua integridade e autenticidade. A língua pode esforçar-se por delimitar o discurso citado com fronteiras nítidas e estáveis o que acentua o grau de firmeza ideológica, o grau de autoritarismo e de dogmatismo que acompanha a apreensão do discurso. (op. cit., p. 148-149). [Já no pictórico], o narrador pode deliberadamente apagar as fronteiras do discurso citado, a fim de colori-lo com as suas entoações, o seu humor, a sua ironia, o seu ódio, com o seu encantamento e desprezo. (op. cit., p. 150).

Se pensarmos especificamente na forma como um locutor pode inserir o discurso citado, tendo em vista os dois estilos propostos por Bakhtin, podemos considerar o discurso direto como pertencente ao estilo linear, portanto muito mais autoritário, dogmático, enquanto o indireto e o indireto livre são característicos da orientação pictória, pois no discurso direto temos todo o esforço do locutor em empregar alguns recursos da língua para manter exatamente as delimitações do discurso citado, ou seja, o locutor, ao citar algo em discurso direto, procura não colori-lo com as suas entoações, o que o torna muito mais autoritário.

As citações no discurso escrito da Igreja Universal são feitas em grande quantidade sob a forma de discurso direto, portanto no estilo linear a que Bakhtin se refere. Esse fato é um forte indício para que falemos em um possível autoritarismo no discurso da Igreja Universal, pois sempre que o pastor propõe uma passagem Bíblica, para em seguida discursar, ele o faz em discurso direto, inclusive com verbos dicendi do tipo: "A Sua Palavra diz [...]", "A passagem bíblica relata [...]", "A Palavra de Deus descreve [...]", "Por isso o Senhor Jesus disse [...]", com os quais, numa aparente neutralidade, o pastor 
exime-se de responsabilidades, nem mesmo a ele sendo permitido qualquer tipo de questionamento, pois trata-se exatamente das palavras de Deus.

Assim, cabe ao fiel unicamente ouvir, crer e pôr em ação a palavra divina. Ao pastor, por ser um agente institucionalmente 'preparado' e ‘autorizado', reserva-se o papel de interpretar para o fiel - muitas vezes carente - os preceitos da Bíblia.

\section{Referências}

AUSTIN, John Langshaw. Quando dizer é fazer: palavras e ação. Porto Alegre: Artes Médicas, 1990. 136 p. . Le langage de la perception. Paris: Armand Colin, 1971.

1979. . Philosophical papers. 3. ed. Oxford: Clarendon Paperbacks,

BAKHTIN, Mikhail. Marxismo e filosofia da linguagem. Trad.: Lahud, M.; Vieira, Y. F. São Paulo: Hucitec, 1999.

BARROS, D. L. P. Teoria do discurso - fundamentos semióticos. São Paulo: Atual, 1988.

BOURDIEU, P. A economia das trocas lingüísticas. São Paulo: EdusP, 1996.

BRANDÃO, H. H. N. Introdução à análise do discurso. 5. ed. Campinas: Editora da UNICAMP, 1996.

CERVONI, J. A enunciação. Trad.: Santos, L. Garcia dos. São Paulo: Ática, 1989.

GUIMARÃES, E. R. J. Modalidade e argumentação lingüística. Tese de doutorado. FFLCH, Universidade de São Paulo (USP). São Paulo: 1979.

KOCH, I. G. V. Aspectos da argumentação em lingua portuguesa. Tese de doutorado. Pontifícia Universidade Católica de São Paulo (PUCSP). São Paulo: 1981.

PIERATT, A. B. O evangelho da prosperidade. 2. ed. Trad.: Malkomes, Robinson. São Paulo: Vida Nova, 1999. 